\title{
PELlOUTIER E O AGENCIAMENTO DAS ORIGENS
}

\author{
Adilton Luis Martins ${ }^{1}$
}

\begin{abstract}
Resumo
Esta pesquisa se comprometeu inicialmente em discutir o processo de representação dos celtas na historiografia anti-absolutista de Simon Pelloutier. Entretanto, as fontes, abordadas metodologicamente pela genealogia, permitiram uma associação epistemológica. Em todas circundavam o tema das origens, ou melhor, todas produziam seu determinado conhecimento histórico com base nas origens. Os conhecimentos históricos e seus comprometimentos sócio-políticos e culturais eram forjados a partir da importância dada às origens nas fontes modernas - numa prática de agenciamento das origens. Este conceito consiste em uma relação epistemológica cultural com o tema das origens presente na historiografia moderna. Ele é pensado, neste estudo, como a identificação de um substrato religioso na noção profunda do sentido de historicidade, que o investe, de modo quase genealógico, com todo o processo de racionalidade erudita.
\end{abstract}

\section{Palavras-Chave}

Simon Pelloutier; Absolutismo; século XVIII; Historiografia; "Agenciamento das Origens".

1 Pós-doutorando, Capes, Universidade Federal de São Paulo, São Paulo, Brasil. E-mail: adiltton@hotmail.com 


\begin{abstract}
This initial aim of this research was to study the process of representation of the Celts in the anti-absolutist historiography of Simon Pelloutier. However, as its sources were approached by the genealogical method, they made way for a new epistemological association. These sources were surrounded by the issue of human origins; or, better yet, each of them produced its own historical knowledge based on a view of human origins. This means that their historical knowledge and socio-political and cultural allegiances were based on the importance ascribed to the origins - as an agencying of origins practice. The agencying of origins concept consists in an epistemological and cultural relation with the theme of human origins in modern historiography. In this study, it is the identification of a religious substance in the deep notion of the meaning of historicity, and its virtually genealogical empowerment by the entire process of erudite rationality
\end{abstract}

\title{
Keywords
}

Simon Pelloutier; Absolutism; 18th Century; historiography; "Agencying of Origins". 
Esta pesquisa se comprometeu inicialmente em discutir o processo de representação dos celtas na historiografia anti-absolutista de Simon Pelloutier. Entretanto, as fontes, abordadas metodologicamente pela genealogia, permitiram uma outra associação epistemológica. Em todas circundavam o tema das origens, ou melhor, todas produziam seu determinado conhecimento histórico com base nas origens. Os conhecimentos históricos e seus comprometimentos sócio-políticos e culturais eram forjados a partir da importância dada às origens nas fontes modernas - numa prática de agenciamento das origens.

Este conceito consiste em uma relação epistemológica cultural com o tema das origens presente na historiografia moderna. Ele é pensado, neste estudo, como a identificação de um substrato religioso na noção profunda do sentido de historicidade, que o investe, de modo quase genealógico, com todo o processo de racionalidade erudita (Grell, 1993:128).

O passado original como memória do início dos tempos, origem de todos os valores, de todas as instituições, todas as línguas, todas as experiências políticas, todas as dominações, todas as conquistas, todas as guerras, todos os costumes; estas origens particulares, narradas na história de um ou de outro passado original universal, nesta perspectiva, era influenciado pela economia da salvação cristã, em especial, a providência divina sobre a história humana. Tema que, por exemplo, pode ser encontrado no pensamento tomista (Woortmann, 2005: 259-314) e medieval da relação entre providência e liberdade.

Para a o Cristianismo, em geral, após a Criação - harmônica e boa, do mundo e do homem, aconteceu a Queda original, por meio da imoralidade, que é o pecado, a descontinuação originária da origem, logo, segundo a economia da Salvação, encontrar-se-á a Restauração Final. A Nova Jerusalém do "Livro do Apocalipse" nada mais é do que a plena e superior expressão do Jardim do Éden, a história é o espaço do homem em busca do seu fim, sob a graça de Deus.

Os conceitos Criação, Queda e Restauração consistem no tripé epistemológico basilar da experiência da temporalidade teológica. A Queda do Homem é sempre um distanciamento original da origem universal, ao passo que a Criação e a Restauração são efeitos imediatos circunscritos a esta mesma origem. Início e fim surgem como os limites da linear narrativa da história do Deus-verdade cristão, que se revela para uma determinada cultura, e acaba por colonizar o eterno retorno arcaico. Uma nova forma de produção de um sentido para todas as coisas tem sido protagonizada pela História judaico-cristã, sempre teológica e hermenêutica. 
Se, por um lado, a compreensão do tempo para o mundo arcaico se estabelece pela solidão ou angústia do dasein heideggeriano (Heidegger 2002,1) em relação ao cosmo e aos os ritmos cósmicos, por outro lado, no mundo judaico-cristão, a compreensão do tempo estratifica-se, em sua formulação histórica, na solidão diante da história (Forte, 1995: 09-10; Eliade, 1992: 11). Ou seja, enquanto que o eterno retorno poderia ser visto como uma explicação para dar sentido à mudança da natureza, a história judaico-cristã seria uma explicação para dar sentido ao homem em relação ao homem, e com o tempo, sob a égide da providência divina.

O tema da minha pesquisa centraliza-se sobre a imagem de si mesmo, formada pelo homem das sociedades arcaicas, e sobre o lugar que ele ocupa no Cosmo. A mais importante diferença entre o homem das sociedades arcaicas e tradicionais, e o homem das sociedades modernas, com sua forte marca de judeu-cristianismo, encontra-se no fato de o primeiro sentir-se indissoluvelmente vinculado com Cosmo e os ritmos cósmicos, enquanto que o segundo insiste em vincular-se apenas com a História (Eliade, 1992: 11).

A origem, para a experiência teológica da historicidade cristã, parte de alguns sujeitos da história e do pensamento histórico. Os sujeitos da história são a providência divina e os homens sob a cruz do tempo em relação ao Deus que se revela (Forte, 1995: 9-10). A interpretação dos sinais dos tempos e da história, por meio da narrativa, cabe aos profetas, que anunciam e denunciam. Em pauta, no profetismo, está a relação moral do povo e as suas consequências teológicas e teleológicas. Este sujeito-profeta da História, narrador onipresente, é uma metáfora para a sua função na historiografia moderna na erudição dos historiadores.

Este agenciamento das origens que produziu o conhecimento histórico se manteve na modernidade. Os historiadores, em geral, tratavam da origem, queda e restauração da origem em seus diversos campos de pesquisa histórica. No século XVIII francês, por exemplo, os romanistas monárquicos versavam da Origem, da Queda, e da Restauração do Império Romano na figura dos imperadores medievais, como Carlos Magno (Dubos); ou, Origem, Queda e Restauração da Aristocracia Franca (Boulainvilliers); ou, ainda, Origem, Queda e Restauração dos Celtas (Pelloutier). 


\begin{tabular}{|c|c|c|c|}
\hline \multicolumn{4}{|c|}{ HISTORIADORES } \\
\hline $\begin{array}{l}\text { Agenciamento das } \\
\text { Origens }\end{array}$ & $\begin{array}{l}\text { Romanistas } \\
\text { Monárquicos }\end{array}$ & $\begin{array}{l}\text { Germanistas } \\
\text { Aristocráticos }\end{array}$ & $\begin{array}{l}\text { Germanistas } \\
\text { Protestantes }\end{array}$ \\
\hline Origem & $\begin{array}{l}\text { Guerra das gálias } \\
58-50 \mathrm{aC} \text {. }\end{array}$ & $\begin{array}{l}\text { Clóvis I - a } \\
\text { consolidação franca } \\
481-511 \text { dC. }\end{array}$ & $\begin{array}{l}\text { Celtas antes das } \\
\text { Guerras das Gálias } \\
58 \mathrm{aC} \text {. }\end{array}$ \\
\hline Queda & $\begin{array}{l}\text { Igreja Reformada na } \\
\text { França - } 1559\end{array}$ & Monarquia absoluta & $\begin{array}{l}\text { Quando o Império } \\
\text { Romano dominou as } \\
\text { Gálias e as fez } \\
\text { províncias (aC 117) }\end{array}$ \\
\hline Restauração & Louis XIV & $\begin{array}{l}\text { Restauração da } \\
\text { aristocracia franca }\end{array}$ & $\begin{array}{l}\text { Restauração do celtas, } \\
\text { que representam os } \\
\text { protestantes }\end{array}$ \\
\hline $\begin{array}{l}\text { Modelo de } \\
\text { historiador }\end{array}$ & $\begin{array}{l}\text { Jean-Baptiste Dubos } \\
(1670-1742)\end{array}$ & $\begin{array}{l}\text { Henri de } \\
\text { Boulainvilliers (1658- } \\
\text { 1722) }\end{array}$ & $\begin{array}{l}\text { Simon Pelloutier } \\
(1694-1757)\end{array}$ \\
\hline Livros & $\begin{array}{l}\text { Dubos, J. B. Histoire } \\
\text { critique de } \\
\text { l'établissement de la } \\
\text { Monarchie française } \\
\text { dans les Gaules. } \\
\text { Paris, Chez Nyon: } \\
\text { 1742. } 3 \text { T. }\end{array}$ & $\begin{array}{l}\text { Boulainvilliers, H. de. } \\
\text { (1727). Histoire De } \\
\text { L'Ancien } \\
\text { Gouvernement De La } \\
\text { France: Avec XIV. } \\
\text { Lettres Historiques } \\
\text { sur les Parlemens ou } \\
\text { Etats-Generaux. Haye } \\
\text { \& a Amsthrdam } \\
\text { (1742). }\end{array}$ & $\begin{array}{l}\text { Pelloutier, Simon. } \\
\text { Histoire des Celtes, et } \\
\text { particulièrement des } \\
\text { Gaulois et des } \\
\text { Germains, depuis les } \\
\text { tems fabuleux, } \\
\text { jusqu'à la prise de } \\
\text { Rome par les Gaulois. } \\
\text { Beauregard (La } \\
\text { Haye) 1740. }\end{array}$ \\
\hline
\end{tabular}

Foram os historiadores eruditos que, ordinariamente, poderiam ser considerados profetas-narradores. A força simbólica (Bourdieu, 1989: 134) de seu discurso, sempre naturalizado socialmente, produziu poder segundo a adaptação dos elementos Origem, Queda e Restauração. O exercício do profeta-narrador era legitimado segundo a fidelidade ao discurso e à presença da graça divina, e, paralelamente, o exercício do historiador-narrador era legitimado com base na fidelidade às fontes que manifestavam a verdade antiga da origem. A graça divina do profeta antigo parecia ser substituída pela emergência da erudição. $O$ erudito 
tinha o capital cultural da memória, sua força estava na naturalização do que dizia.

Por outro lado, o agenciamento das origens, da narrativa erudita, expressava um discurso sobre o presente. A glória da "Cidade de Deus" agostiniana presente na monarquia absolutista do Abade Dubos era a versão "restaurada" do decaído Império Romano, seu presente era "Restauração". A queda da liberdade da aristocracia franca, entendida como a queda do verdadeiro sustentáculo da França, era entendida pelo historiador-profeta- narrador Boulainvilliers como as dificuldades da nobreza sob o Absolutismo. Para ele, o presente era "queda". Facilmente este discurso aristocrático poderia ser associado ao celtismo de Pelloutier.

Não obstante posições políticas contrastantes e até formações teóricas diferentes, estes autores produziram o conhecimento histórico por intermédio do agenciamento das origens, que tinha uma atividade autoreguladora - a escatologia ou a teleologia - que impunham um rumo ou um objetivo político do "narrador-profeta-historiador".

Na origem estava a história do homem universal inteira, a sua queda e a promessa de restauração - que deveria ser considerada em seus condicionantes morais e políticos. Na queda estava a origem e o homem vivia sob o peso das desventuras e a necessidade da restauração. A história se contava no interstício entre a queda e a restauração. Na restauração, origem e queda se justificavam e legitimavam o futuro - que era cumprimento, na história, dos condicionantes.

Para ilustrar o que estava sendo dito, pode-se dizer que, não sem razão, a história do Império Romano no século XVIII foi a raiz imaginária de toda a historiografia francesa. Ela era modelo e/ou referência modelar. Um conhecido debate na Académie de Inscriptions et Belles Letres tratou da discussão a respeito das origens de Roma.

Este debate, para Chantal Grell, não desempenhara apenas uma discussão a respeito do tema, mas também da capacidade da história erudita de superar as fábulas e as lendas. Tal debate, entre 1722 - 1725, não só suscitou novas discussões em meio ao universo erudito, como pode ter influenciado diretamente outros autores, como Simon Pelloutier.

Seria, portanto, a "Histoire de Celtes et particulièrement des Gaulois et des Germains, depuis les temps fabuleux jusqu'à la prise de Rome par les Gaulois" (1742) e "Dissertation sur l'origine des Romais" (1753), títulos-temas submetidos à influência desta discussão? De qualquer forma a presença dos romanos não era uma novidade para a historiografia classicista, pelo contrário, era a grande chave de leitura. 
Além disso, a leitura das fontes elencadas para os fins desta pesquisa tratam das origens. Uma forma de compreendê-las é o estudo das suas maneiras de produção em relação à cultura em suas formações discursivas, ou seja, "aquilo que numa conjuntura dada, determinada pelo estado de luta de classes, determina o que pode ser dito" (Pêcheux, 1996:160).

Este trabalho versa sobre esta relação entre origens e política. Compreende que os enunciados históricos extremamente bem elaborados pela erudição de seus autores são realizados de maneira sempre parcial, a partir da experiência sócio-política e cultural do enunciador. Este tema, que se associa ao tema dos "usos do passado" e da metodologia arquegenealogista, por meio do procedimento de leitura das fontes elencadas, estará presente em todo o trabalho, compreendidas no conceito de agenciamento das origens. Neste artigo, introduz-se esta problematização a partir do trabalho de Pelloutier.

Celto-germanista, Pelloutier, que se posicionava contra a experiência absolutista, cuja gênese epistemológica jurídica-política encontrava-se no Império Romano e na Igreja Romana produziu, por meio do "agenciamento das origens", a desqualificação destas raízes. Para o autor, o tema da Queda do Império Romano era a restauração da origem obscura que ele apresentava.

Pouco pode ser dito a respeito da vida de Pelloutier, os dados biográficos são raros (ver Anexo), entretanto, alguns documentos, em geral do século XIX, permitiram pensar as influências de sua vida em sua obra. O que não quer dizer que são dimensões motoras ou causais necessárias.

Nasceu em 27 de outubro de 1694, sob o Absolutismo de Luís XIV, em Lion, foi conselheiro eclesiástico do Rei da Prússia Frederico II, Pastor de Werder, assessor do Collége Français em Berlim, membro e bibliotecário da Académie des Sciences de Berlin². Morreu em 03 de outubro de 1757.

Seu pai, Jean Pelloutier, era comerciante e sua mãe chamava-se Françoise Chaparéde. Devido à revogação do Édito de Nantes, seus pais foram para Leipzig, onde o pai nasceu. Esta fuga se deu principalmente pela perseguição imediata aos protestantes franceses. $O$ Édito de Fontainebleau (1685). Sua vida profissional parece ter sido toda dedicada

2 Os documentos oficiais desta instituição foram publicados em francês durante o século XVIII. 
aos estudos dos celtas e à teologia, eis um retrato pintado de Pelloutier no século XIX por historiadores do protestantismo francês.

Seu objetivo, no entanto, enfrentava problemas extremamente sensíveis à historiografia do século XIX, que, para Emile Haag, foram superados; apesar dos celtas não terem deixado monumentos de sua existência, a não ser algumas pedras isoladas, cantos populares de uma autenticidade duvidosa, narrativas incompletas e vagas, por vezes contraditórias, Pelloutier venceu esta problemática com imensas leituras, "livre de preconceitos" para discernir o verdadeiro, do verossimilhante e do falso. Assim, pôde determinar os graus de probabilidade de cada asserção (Haag, 1783-1882: 113).

A conclusão desta pesquisa versa exatamente sobre o pensamento e a pesquisa histórica de Pelloutier, associado a uma disputa historiográfica ocorrida na França, na primeira metade do século XVIII, entre Boulainvilliers e o abade Dubos. Apesar de longínquos e de abordarem objetos diferentes, parte-se para uma compreensão a partir do agenciamento das origens, que foi o meio pelo qual o pensamento histórico obteve sua autoridade de legitimação jurídica, em relação à França Absolutista. Por isso, excluíram-se interpretações centradas no meio social de cada um dos autores. Não é uma discussão da história das ideias, nem de história social, tão pouco marxista. O que se pretende aqui é um estudo pós-estruturalista mesclado à História Cultural. A pesquisa limitou-se a Pelloutier, em especial, a quatro textos presentes nos dois primeiros tomos da "Histoire de Celtes" (1740).

Como enunciado, para Pelloutier a origem da Europa estava no mundo celta. Assim, ele se posicionava contra a ideia de Roma ou da Grécia como origem primeira, fundacional da cultura europeia. Antes de discutir os desdobramentos deste enunciado, sem perder o fio condutor deste artigo, as seguintes questões devem ser consideradas: Quem eram os celtas de Pelloutier? Por que os celtas? Como escreveu as suas histórias?

Para introduzir a discussão observa-se o prefácio da "Histoire de Celtes". Entretanto, não se pode ponderar a "Histoire de Celtes" sem considerar seu retro-espelho que é a história de Roma. Também, deve-se levar em consideração que apesar de Pelloutier ser um autor cristão, o tema da providência divina estava ausente em seus escritos históricos. A História era o lugar da liberdade, o que queria dizer que tudo poderia ser transformado: cultura, governo, religião. Deste modo, os celtas não eram apenas o povo escolhido como instrumento divino. Eles eram a origem da Europa e da civilização europeia. O terceiro tomo da "Histoire des Celtes", que não será analisado aqui, trouxe esta ideia com maior clareza. A 
liberdade dos celtas era a liberdade abençoada por Deus, a experiência mística da história pertence ao homem.

É possível visualizar estas considerações no prefácio:

Para bem reconhecer os celtas em todos os seus diferentes aspectos, é preciso considerá-los como eram antes que os fenícios, os gregos e os romanos entrassem em seu país, quando eles foram submetidos em parte. O comércio e a dominação dos estrangeiros produziram, como eu mostrarei, as grandes mudanças nas suas leis, na sua religião e, em geral, em toda a maneira de viver. É preciso tomar estes povos no bruto, sim eu ouso me servir deste termo, e descobrir se é possível saber o que eram antes de adotarem as ideias e os costumes estrangeiros (Pelloutier, 1740: XXXVII).

Era a relação com outros povos que fazia as mudanças culturais e não a providência divina. Segundo Georges Lefebvre, o pensamento historiográfico do século XVIII seria influenciado pelas suas necessidades sócio-políticas próprias e pela herança do século XVII. O que se entendia por esta herança seria o racionalismo, que destituiria a História de seu aspecto científico, considerando as influências de Isaac Newton, René Descartes e Benedito Espinosa, que afetaram a historiografia francesa, assumindo um aspecto de História Novelesca - de verdades despreocupadas com as fontes (1971: 172). Em Bossuet identifica-se uma resistência severa contra estes posicionamentos racionalistas.

Entretanto, há uma diferenciação entre as fábulas e as lendas das referências críticas às fontes antigas, esta era uma marca de Pelloutier e da erudição do século XVIII:

É isto que me determinou a tomar a história dos celtas como tão elevada, que o pouco das passagens que nos restam me permitiu remontar. Mas, como a primeira Época desta história, que começa nos tempos fabulosos e termina no ano da tomada de Roma pelos gauleses, não suscetível a uma ordem cronológica, eu tomo a parte a seguir na ordem das matérias, a antiga barbárie dos povos celtas. Vendo-lhes sair sucessivamente, muito cedo, e outros mais tarde de acordo com a sua vizinhança coma as nações policiadas (Pelloutier, 1740: XXXVIII).

Esta última citação, não apenas permite ter uma ideia da necessidade de textos antigos para a erudição poder superar as exigências do racionalismo, mas, também, autoriza ponderar a respeito da hierarquia dos textos da Antiguidade. Não bastava ter em mãos uma citação antiga, elas poderiam ser contraditórias ou fabulosas. A questão para a erudição, influenciada pelo racionalismo, em especial, a partir de Espinosa e de Richard Simon, era como estabelecer a verdade e a legitimidade. 
Uma primeira hipótese norteou esta pesquisa: para Pelloutier, os autores que estiveram entre os gauleses e os germanos eram mais importantes que os autores que não estiveram entre eles. $\mathrm{O}$ argumento que sustentava esta hipótese era o da presença da influência do empirismo no pensamento da Europa continental. Mas, este argumento possuía alguns problemas, o primeiro era que basicamente confundia racionalismo com empirismo. Racionalismo deveria ser entendido como a ordenação do conhecimento segundo a razão, ordem do mundo, subjugando os sentidos à lógica. O empirismo, pelo contrário, tanto em John Locke como em David Hume, procurava dar a experiência dos sentidos a primazia, fazendo com que a dedução e a indução fossem efeitos de dimensões psicológicas.

Sabe-se, também, da resistência do Cristianismo ao empirismo. O realismo cristão aceita com maior facilidade a lógica racional ao empirismo sensualista. Enfim, o argumento da influência do empirismo foi deixado de lado.

Para dar uma explicação às escolhas de Pelloutier para a hierarquia das fontes da Antiguidade, optou-se aqui por outro argumento epistemológico, que, no entanto, está mais associado às práticas culturais do século XVIII.

Não é um bom procedimento justificar estruturas epistemológicas apenas em dimensões filosóficas, e o mesmo deve ser dito da exclusão total da influência de modelos filosóficos na estrutura da pesquisa histórica. Primeiro porque raramente se encontra um cientista radicalmente orientado por um modelo de pensamento. Segundo, porque a ciência está inserida em uma dinâmica heterogênea que ultrapassa o mero racionalismo, ou melhor, porque compõe formas racionais heterogêneas, associando-se a elementos não racionais.

Sem se deter nos críticos da racionalidade moderna, como Jean François Lyotard e o seu tripé "lei, forma e acontecimento", ou Gilles Deleuze e o pensamento nômade, a pesquisa a respeito de Pelloutier preocupa-se em justificar a hierarquia das fontes nas práticas culturais, que são práticas epistemológicas também.

Neste período, as práticas culturais referidas eram as narrativas de viagem. Estas crônicas permitiam uma compreensão da hierarquia das fontes. Neste aspecto, os viajantes narradores da Antiguidade, como Estrabão (1740, XLIV), Júlio César, Tácito, Plínio (1740, LII), Possidônio (1740, LV), Agátias (1740, LVII) tinham o mesmo valor que os viajantes narradores modernos. 
O valor destas narrativas de viagens era mais que socioeconômico, estava longe de ser apenas efeito da curiosidade ou instrumentalização de empresas coloniais e missionárias. A importância delas não devia, portanto, ser reduzida a conhecer para colonizar, conhecer para converter, ou conhecer pelo prazer de se saber. Estas narrativas impunham no espaço epistemológico preocupações teológicas, históricas e identitárias, assim como políticas e econômicas.

Preocupação teológica porque era necessário explicar a razão de Adão ser pai de todos, dos europeus, dos negros, dos asiáticos e dos povos americanos. Preocupação histórica, porque submetia a própria compreensão do tempo ao se olhar os selvagens, que traziam as origens remotas da história na contemporaneidade. Identitária, porque fazia com que o europeu se impusesse diante do que estava fora de sua civilização. A comparação tornava-se meio explicativo para a moral europeia, como, por exemplo, os males da civilização e a felicidade primitiva, relacionados aos conceitos de "bom selvagem" e de "homem natural". Um exemplo clássico é o do Padre Lafitau.

Para o padre Lafitau, o homem era um ser único, o que diferenciava era o grau de civilização, representada pela cultura e religião. Suas pesquisas eram uma busca constante de paralelos, que variavam em suas determinações, mas que destacavam, sobretudo, símbolos culturais, procurando dar sentido a uma ideia universal de homem religioso:

selvagens e de me informar de seus costumes e suas práticas, procurei em suas práticas e em seus costumes vestígios da Antiguidade mais recuada; li com cuidado aqueles autores mais antigos que trataram dos costumes e das leis, e dos usos dos povos dos quais tiveram algum conhecimento; fiz a comparação deste costumes com os outros, e confesso que se os autores antigos me dão luzes para apoiar minhas conjecturas felizes tocando os selvagens, os costumes selvagens, me dão luzes para entender mais facilmente, e para explicar muitas coisas que estão nos autores antigos (Lafitau, 1724: I, 3).

Com base nestas afirmações, confere-se mais credibilidade à hipótese da preferência que Pelloutier tinha por autores antigos que visitaram, ou melhor, viveram nos países de sua narrativa e que isso não era por influência do empirismo inglês, mas sim pela necessária confiabilidade nas narrativas de viajantes, que justificavam a identidade europeia frente aos "selvagens". Em Pelloutier, pode-se encontrar várias referências aos povos americanos, por exemplo, quando este precisava discutir se os antigos europeus eram antropófagos:

Não é necessário se surpreender que os antigos habitantes da Europa fossem antropófagos. Muitos povos americanos o são ainda hoje. Não provam nada, acusam mal a respeito, sem nenhum fundamento, os celtas de comerem 
homens. Os viajantes, que nos dão relatórios da América, são dignos de fé, pois eles relacionam os povos antropófagos que se encontram em diferentes partes deste vasto continente: degolar, assar, comer seus prisioneiros. Eles produziram uma infinidade de exemplos. Ao contrário, ninguém diz ter visto os celtas nestes excessos (Pelloutier, 1740: 63).

Por isso, uma vez que a confiança às narrativas era um a priori cultural que Pelloutier depositou na distribuição da autoridade das narrativas antigas, este trabalho deriva daí sua conclusão a respeito do empirismo.

Alguns trechos de Pelloutier permitem uma maior clareza a este respeito:

Estrabão (...) há um bom tempo, desejou enriquecer sua Geografia de uma exata descrição de todos os países que eram ocupados pelos povos celtas (2) Strabo Lib. II (Pelloutier, LV). (...) (...) Posidônio merece muita atenção, por que este autor viajou na Gália (Pelloutier, 1740: LV).

Enfim, em um contexto mais geral da pesquisa, este argumento permite compreender a influência do universo cultural no trabalho de Pelloutier. Para ele, a hierarquia das fontes era realizada em virtude da credibilidade das narrativas das viagens modernas. Ele aliava metodologia e sua experiência cultural na produção de seu texto.

A rigor, o argumento não deve ser considerado como suficiente. É necessário observar este encontro em uma dimensão mais epistemológica ainda. Se, por um lado, a credibilidade das narrativas de viagem promovia no intelectual europeu discussões de cunho teológico, histórico e identitário, que acabavam em práticas políticas como a legitimação da escravidão negra, a divisão das colônias, a catequização dos selvagens, por outro lado, as reflexões morais a respeito do homem europeu produziam os primeiros passos de uma Antropologia (Duchet, 1975: 7-28; Lemay, 1975: 29-40).

O agenciamento das origens, certamente, está implicado no conceito de agenciamento. Para Deleuze, um agenciamento seria um território de signos. Este território proporia uma dupla articulação, um sistema semiótico (expressão) e um sistema pragmático (conteúdo). Em suma, num agenciamento dever-se-ia perguntar o que se fala e o que se faz. (Deleuze (5), 1997: 218).

O que se diz seria a sociedade europeia moderna. O que se fazem seriam narrativas e estudos sobre as origens da Europa. Fazer a história dos celtas, por exemplo, não seria dizer que os celtas eram europeus, mas que eles eram a autêntica origem da civilização e o "verdadeiro sentido" de ser civilizado. Fazer uma narrativa sobre como viviam os americanos 
selvagens permitiria entender os "avanços da civilização europeia" e a própria origem desta civilização.

Outra articulação do agenciamento consistiria na territorialização e na desterritorialização. Na dinâmica da territorialização, tudo caminhava para um conjunto de verdades, a saber, o homem europeu, do qual se deduzia a caracterização de outros homens e, assim, construía-se um "homem universal", com diferenças apenas em relação à cultura civilizada ou a sua falta. Na desterritorialização, encontrar-se-ia a crítica imediata a este homem civilizado, sua fraqueza viciosa (Rousseau), seu sistema absolutista fadado ao fracasso (Montesquieu), suas superstições cristãs (Voltaire) que retardavam o progresso. Falar das origens seria inscrever certezas identitárias e também produzir a sua crítica.

Seria importante uma pesquisa mais rigorosa comparando a origem da Europa e a origem de outros povos. Entretanto, esta pesquisa parte da hipótese geral de que havia um mesmo processo nestas construções narrativas, elas partiam de um mesmo espaço simbólico para se traduzirem em identidade de civilizados. Este complexo jogo de signos estava agenciado na ideia de origem.

Como em Lafitau, preocupado com as origens, o primeiro capítulo da Histoire des Celtes tratou da origem dos celtas. O livro primeiro se intitulava A origem dos Celtas, e seus conteúdos eram: "dos países que seus povos ocupavam antigamente"; "dos diferentes nomes que eles traziam" e "da língua que falavam nos primeiros tempos".

$\mathrm{O}$ capítulo $\mathrm{X}$ do primeiro tomo definiu as origens, após isto o autor percorreu inúmeros documentos da Antiguidade greco-romana para definir os costumes de cada povo celta, a saber, sauromatas, celto-citas, íberos, gauleses e germanos, getas, para provar que eram todos o mesmo povo.

Eu não me comprometeria a examinar os vários nomes que o povo celta usava, se essa pesquisa, por mais interessante que fosse, não poderia ser de alguma utilidade para descobrir certos costumes das nações celtas, por nomes que lhes foram atribuídos (Pelloutier, 1740: 137).

A adaptação cultura-ambiente e ambiente-sociedade explicaria as diferenças em todo o mundo; o nomadismo e o sedentarismo eram as formas pelas quais as sociedades procuravam o melhor ambiente as suas necessidades, sobretudo segundo a vontade de Deus. Com isto não se ausentaria $\mathrm{o}$ aspecto físico, mas a explicação não poderia ser desenvolvida em termos naturais. $O$ objeto de diferenciação não era, 
necessariamente, apenas o corpo, mas o ambiente (clima) e a sociedade (cultura e aspectos bio-físicos).

Estes determinantes permitiram que Pelloutier afirmasse:

É certo que a maioria dos povos celtas eram anteriormente nômades. II) ou seja, não tinham morada fixa. Eles não construíram casas ou cabanas, mas passaram toda a vida em carruagens e paravam em uma terra somente, enquanto encontravam para seus rebanhos o que eles poderiam dar subsistir. Quando os povos celtas começaram a se instalar em uma terra, no entanto, eles não pensavam, nem para construir cidades, nem para se fechar. Cada indivíduo se instalava em uma floresta, ao pé de uma colina, ao longo de um ribeiro, no meio de um lugar, em que gostavam, de caçar, de pescar ou de agricultura (Pelloutier, 1740: 138).

Estes nômades que se estabeleceram se originaram, geográfica e teohistoricamente, segundo uma narrativa em que o milagre era o meio explicativo da diversidade de pessoas e a diversidade de localizações:

Deus não se apraz enquanto não revogar a dúvida de que nos diz a Escritura Santa, quando nos apresenta o gênero humano, contudo, descendente de um só homem. Mas a criação de um homem, a longa vida dos patriarcas, a conservação do homem, das plantas e dos animais em meio ao dilúvio universal, são os milagres do poder divino. Deus pôs uma diferença sensível, entre os diversos descendentes de Adão, ou de Noé, que se poderia distinguir até o fim do mundo, os germanos dos lapões, os povos brancos dos povos negros, daqueles que têm cabelos crespos daqueles que os tem longos e soltos ao vento (Pelloutier, 1740: 201).

Ainda em 1770, o reeditor da "Histoire des Celtes", Pierre de Chiniac, comentava em nota este parágrafo, a posição do comentador talvez estivesse muito próxima ao Iluminismo, quando preferiu dar uma interpretação mais racional às diferenças. Certamente, para ele, as diferenças físicas entre os homens não procediam de um milagre posterior ao dilúvio, mas, sim, da adaptação física ao clima pelos séculos.

A tese de Pelloutier afirmava que os celtas foram criados para se encontrarem na terra preparada para eles pelo criador. A associação entre terra e povo era o agenciamento de legitimação muito conhecido para designar a posse das terras. Um exemplo de aplicação, estava na guerra contra a Holanda, anexação da Alsácia, sob Luís XIV, e a destruição da ponte sobre o Reno, em 1672, justificadas pelo De Bello Galico (A Guerra das Gálias). Portanto, era o texto antigo que determinava as regiões dos gauleses, assim, sob o ponto de vista da história absolutista, a Germânia ficava além do Reno. A apresentação dos gauleses era geográfica e também inserida no binômio terra e povo. Enfim, para Pelloutier, os 
celtas eram originados no milagre da diferenciação dos homens após o dilúvio. Eles se encontravam na terra criada para eles, que era a Europa.

Para Pelloutier, os celtas foram conhecidos primeiramente pelo nome de citas, nome que os gregos deram a todos os povos que habitavam ao longo do Danúbio. Entretanto, Pelloutier desconfiava, constantemente, da precisão de suas fontes históricas.

Sua empresa precisava definir a Antiguidade dos celtas para fixar sua identidade, que era geográfica, e que tinha seu correspondente jurídico no direito à posse da terra. Entretanto, havia uma dificuldade real para definir, por meio dos textos antigos, esta identidade. Ele, então, procedia da seguinte maneira, usando Estrabão para anunciar o problema:

Estrabão nos ensina que os autores (Estrabão. Liv. XI, 507) da primeira Antiguidade distinguem os citas estabelecidos sobre o Ponto Euxino, do Danúbio e o mar Adriático, em hiperbóreos, sauromatas e arismaspes; e aqueles que estão para além do Mar Cáspio, em Saces e Massagestes. Os primeiros estavam, pois, estabelecidos na Europa. Os outros tinham sua residência na Ásia (Pelloutier, 1740: 2).

Em seguida, localizava, para o seu leitor, os povos que estavam próximos aos seus celtas, explicando os nomes antigos e os referenciando no mundo moderno:

Os Sauromatas, ou sármatas, são conhecidos ainda hoje sob o mesmo nome: ele serve para designar os povos que falam a língua eslava, os moscovitas, os poloneses, os boêmios, os vênetos e muitos outros (Pelloutier, 1740: 2).

Seu próximo argumento era explicar que não havia hiperbóreos. Na verdade, este era um erro daqueles que não haviam visitado a Europa para além do Danúbio:

Os hiperbóreos são os celtas estabelecidos ao redor dos Alpes e do Danúbio; provar-se-á após algumas reflexões preliminares que convém fazer a este tema. Os antigos os deslocaram para além dos Montes Ripheéns (Solino cap XXXVI; Plinio. Hist. Nat. Lib IV cap XII p. 471; Estrabão Lib I p. 62; Pomponio Nela lib III cap XV p. 305 Stephano de urb p 654-727), para os mais antigos autores os Montes Ripheéns (sic). Desejava-se ainda que os hiperbóreos fossem situados sob o Polo Ártico, e que, por conseguinte em um clima extremamente frio, onde o ar era sempre emplumado (Solino, cap XXXVI), ou seja, pleno de neve, e onde, o sol não aparece mais que seis meses do ano. A opinião comum era que o vento do Norte [boreal] sobretudo dos Montes Ripheéns (Apolônio diz que as fontes do Danúbio, que quer dizer, além do sopro do vento boreal nos montes Riphéens. Hyperborei Supra Aquilonis Flatum habitatis [ver Apolônio liv IV v 285; Festus P. Dica, 297; Virgílio Geo.. III v. 196]. Nisto, conclui-se que este vento não soprava no lugar dos povos que habitavam além. É por esta razão 
que lhes deram o nome de Hiperbóreos ou de pessoas que residiam além do vento norte (Pelloutier, 1740: 2-3).

Para Pelloutier, somente após a presença dos autores nas Gálias e na Germânia pôde-se observar o erro dos antigos:

Esta falsa ideia foi uma fonte de erros para os geógrafos e para os historiadores que escreveram nos séculos seguintes. Quando os gauleses e os germanos foram descobertos, percebia-se que o vento norte aí soprava como por alhures, não se encontrava aí nem aquela terra vizinha do polo e sempre coberta de neve, nem aquele dia e aquela noite que alternavam apenas a cada seis meses como os antigos falaram. Precisou-se, pois, sempre recuar para o norte estes Montes Ripheéns e os povos que eram assentados aos pés destas montanhas, as colocavam em qualquer país desconhecido, num clima onde ninguém havia ainda penetrado (Pelloutier, 1740: 3-4).

Outrossim, apresentou o problema nos documentos da Antiguidade a respeito dos hiperbóreos com o auxílio dos escritos de Etienne de Byfance, autor moderno cuja referência não foi encontrada, em que ele estabelecia o seguinte quadro: para Stephano de Urb $(7,27)$, os hiperbóreos habitavam em torno do Danúbio; outros autores, que viveram em seguida, colocaram os hiperbóreos nas extremidades setentrionais da Europa, é o caso de Plínio (História Natural liv IV cap XII 464-471), Virgílio (Geórgicas liv III 381, liv XIII 517), Pomponio Mella (liv III cap V p77), Solino (cap XXXVI), Lucano (liv III v 272) e Estrabão (I p.62), outros colocaram os hiperbóreos em uma ilha do oceano, como no caso de Diodoro de Sicília (liv II p.130). Outros, ainda, colocaram ao norte, como Valério Flaco (liv II, v 519), Marcial (liv VII p. 91, IX 127, 36) e outros.

O fato de não terem convivido com os hiperbóreos indicava sua impossibilidade de justificar sua localização. Logo, a diversidade de lugares que eles poderiam viver era proveniente das próprias viagens e da colonização romana, que não os encontravam. Estas viagens localizavam apenas os celtas, logo, era necessário redirecionar a sua região. Portanto, o valor ou o direito da narrativa verdadeira possuía aquele que conviveu com o povo narrado. Apenas no século XVI, com Philipp Cluver, em sua Germania Antiqua, não restaria mais dúvida dos erros dos antigos, para Pelloutier:

Ele prova também que os verdadeiros hiperbóreos, os povos que não viam o sol durante seis meses do ano, deveriam ser colocados ao lado da Groenlândia ou da Nova Zelândia, isto quer dizer, em um país que os antigos não conheceram (Pelloutier, 1740: 5).

Assim, o convívio em meio ao um povo era a fonte da legitimidade da história ou das narrativas. Ao se referir a Posidônio de Apamea, que, 
segundo Cluvier, entendeu que os Montes Riphèens eram, na verdade, os Alpes, escreveu: "A autoridade deste deve ser de um peso muito grande, pois ele viajou nas Gálias" (Pelloutier, 1740: 8). Observa-se, novamente, aqui o domínio do olhar.

Ao contrário, quando tratava da narrativa de Aristeu de Preconésia, que Heródoto citou no livro IV, em que o autor a descreveu a terra dos Arimaspes, compreendido como a primeira referência aos Hiperbóreos, Pelloutier o chamou de charlatão e impostor:

(...) um homem que desejou fazer passar uma obra tão extravagante por uma história verdadeira, que se vangloriava por ter percorrido o país dos arimaspes de um lado a outro, merecia bem que o chamassem assim de charlatão (Pelloutier, 1740: 10).

Destarte, ele resolveu o problema das citações antigas, hiperbóreos e Arismaspes eram referências fabulosas. As pesquisas referenciadas nestas fábulas acabaram por confundir povos como os celtas, que circundavam os Alpes pelos hiperbóreos, como era o caso de Posidônio de Apaméia, ou os Evergetas, pelos Arimaspes.

Uma vez determinadas as confusões e se mostrando iconoclasta das fábulas, ele procurou, utilizando-se dos sármatas, a identidade dos celtas. Os sármatas, que não eram culturalmente celtas, viviam no oriente, eram os hunos.

Na primeira Antiguidade, via-se uma diferença

sensível, e uma espécie de oposição entre seus costumes e os de outros celtas, iam todos à guerra, mas eles não tinham mais que a cavalaria, ou melhor (Tácito, Germ: 46), eles estavam sempre sobre o cavalo, onde viajavam, vendiam, compravam, tinham suas reuniões, faziam suas refeições e seus sonos sobre os cavalos (Amiano Marcelino, liv XXXI: cap III, 615; Zózimo, liv IV: cpa XX) (...), eis a verdadeira origem dos Centauros (Pelloutier, 1740: 114).

Depois disto, para evidenciar a existência dos celtas como portadores de uma cultura única, por meio da erudição, usou de inúmeras citações para criar uma comparação das culturas, algo comum nos relatos de viagens. Entretanto, não apenas nestes aspectos, ao longo do texto de Pelloutier estabeleceu outras comparações. Uma das mais repetitivas era aquelas que fazia uso da filologia.

É preciso, no entanto, notar aqui as dificuldades na definição da identidade celta em Pelloutier. Na verdade, o mosaico de autores da Antiguidade e de referências culturais aos diversos povos na extensão de toda a Europa impedia o uso de um só termo para designar os seus celtas. 
Para provar que os celtas eram um povo único, com pequenas distinções regionais, com nomes diferentes devido a confusões dos antigos, era preciso comparar a outros povos cuja diferença era ainda maior. A diferença com estrangeiros era o meio estratégico de identidade para os Celtas.

Ao usar os sármatas como o "outro" dos celtas, e sem acesso a informações homogêneas dos textos da Antiguidade, Pelloutier precisou fazer comparações entre os não celtas e os celtas. Não a partir de celtas em geral, mas sim com povos fragmentados a quem ele chamou de celtas.

Sua única documentação era heterogênea e o critério do convívio não era capaz de impedir as contradições. Como fazer dos gauleses e dos germanos um mesmo povo? Os documentos antigos assinalavam entre eles muitas diferenças. Sua saída era contrapor os seus celtas aos povos muito mais diferentes deles, como os Sármatas e Romanos. O seu trabalho filológico referia-se a isto. Ao comparar a língua dos Sármatas e a língua dos Getas seu argumento fazia com que o leitor pensasse que os celtas tiveram uma língua apenas (Pelloutier, 1740: 26). Todos os povos celtas, que ele fazia menção em seu livro (Plínio), tinham originariamente a mesma língua, mas se dividiram, em seguida, em uma diferença. Assim, concluía que a língua alemã era um resto da antiga língua dos celtas.

É preciso, inicialmente, estabelecer que os povos celtas falavam, antigamente, a mesma língua. Isto está provado pelo testemunho de autores que o asseguram positivamente: (Tácito, Agrícola: p. 172; cap. 2; Germânia, 45; Plínio Historia Nat. Liv. XXXVII: cap III) (Pelloutier, 1740: 246).

Os celtas eram um povo que Deus criou para habitar a Europa, cuja cultura e instituições originárias eram por direito a verdadeira liberdade. Pode-se dizer, em geral, que os celtas ocupavam

as partes ocidentais da Europa: a Espanha, as Gálias, os três reinados da GrãBretanha e da Germânia, os Reinados do Norte, com uma parte da Itália (Pelloutier, 1740: 21).

A obra em três tomos de Pelloutier queria dizer isto. O título, traduzido aqui, História dos Celtas, e particularmente, dos gauleses e dos germanos, desde os tempos fabulosos, até a tomada de Roma pelos gauleses possibilita uma compreensão. A ideia consistia, realmente, em contrapor a Roma ao o mundo celta.

O mundo celta de Pelloutier era composto pelos reinados do Império Germano e pela França. O mundo romano era a presença do catolicismo sediado em Roma e suas instituições; seu objetivo, libertar os celtas, 
restituí-los à condição original; sua primeira tarefa, legitimar, historicamente, a religião protestante, vinculando-a às origens da Europa e justificar a prática da eleição do governante.

Não se pode afirmar que o texto defendesse a aristocracia, mas, certamente, era um texto anti-absolutista. Seu projeto político estava configurado, por exemplo, nestas passagens:

os celtas eram divididos em cantões, em povos e nações. Chamava-se Cantão (Pagus) um distrito ocupado por certo número de famílias, que tinham seu juiz particular, e um Mallus, quer dizer, um tribunal onde a justiça se administrava por todo o Cantão. Um povo (civitas, populus) era um Estado independente, soberano, formado pela união de diversos cantões. Por exemplo o povo dos Helvéticos (Cesar, I:12) era composto por quatro cantões. Estes povos tinham ao começo de cada primavera uma assembleia geral; todo homem livre e capaz de portar armas, era obrigado a aí tomar parte: aí se decidia, sob a pluralidade de vozes, todos os assuntos que poderiam interessar ao bem do Estado (Pelloutier, 1740: 139).

Os celtas desqualificavam Roma. $\mathrm{O}$ ataque a Roma era o ataque às instituições que se legitimavam em suas imagens. As origens de Roma eram obscuras, assim como os impérios,

Não precisa estar surpreso que a origem dos maiores impérios seja, ordinariamente, obscura e incerta. Os primeiros começos eram pequenos e quase imperceptíveis. O valor, a prudência, a equidade e a temperança tiram os povos da poeira, e os tornam dignos e capazes de dominar os outros. Mas elas são insensíveis para o progresso, no lugar delas, o luxo, a moleza, a violência, são capazes de reverter ao término de alguns anos, o que a virtude não produziu mais que em uma longa continuidade de séculos. Isto é o que eu desejo dizer, seu destaque, particularmente, na História do Império Romano. A ruína deste Império e as causas que lhe são atribuídas não são ignoradas por ninguém. Sua origem, sem remontar aos tempos fabulosos, não deixa de ser a das mais incertas (Pelloutier, 1771: 204).

Valor, prudência, equidade e temperança eram características pertinentes ao mundo dos "bárbaros", em especial, aos celtas. O valor da liberdade, a prudência da aristocracia guerreira, a equidade dos direitos entre os guerreiros e a temperança de optar pelo melhor de sua tribo eram as marcas dos celtas em Histoire des Celtes, e eram apresentadas como a grande origem de todos os povos europeus.

A instituição imperial não pertencia ao universo da cultura bárbara, nem mesmo grega, para Pelloutier. As virtudes que desenvolviam um povo, na sua leitura, poderiam se perder nas desventuras do luxo das cortes, na moleza da civilização e na violência gratuita como espetáculo. A origem do Império Romano não era a mesma que a dos povos bárbaros e gregos. O império seria uma "queda" da cultura original; seu início obscuro, seu 
fim, a ruína. No entanto, a origem dos povos bárbaros teria sua restauração na queda dos impérios: o tema da invasão. Então, cada historiador utilizava-se, várias vezes, do mesmo agenciamento da origem, a ponto de produzir, no interior de uma grande narrativa, pequenas narrativas. Compunham-se, portanto, um mosaico de acontecimentos.

Se, por um lado, os celtas foram antecessores dos troianos como pensava Pelloutier, os antigos troianos eram um povo cita, que tinham passado da Europa para Ásia menor, e aí fundado o Reinado de Tróia $(1772,195)$, por outro lado, os gregos e os romanos não tinham uma origem bem definida, eram apenas considerados inimigos dos celtas,

Inimigos das nações estrangeiras, (os celtas) se dizem, sobretudo, dos gregos e dos romanos, que desejavam a sua liberdade, eles os olhavam raramente com bons olhos. Desde que eles saíram da barbárie, perderam este olhar orgulhoso e terrível ao qual se reconheceria outra vez (Pelloutier, 1771: 118).

Diante dos celtas, os romanos lamentavam ter perdido as virtudes dos bárbaros, Pelloutier contrapunha a civilização greco-romana à cultura celto- bárbara. A oposição dos celtas, que para Pelloutier era formada por toda a Europa, com exceção da Grécia e de Roma, contra a civilização romana, pertencia ao um mesmo dispositivo. As origens europeias eram virtuosas ao passo que as origens do Império Romano eram obscuras e dobráveis aos vícios. A origem de um império era a queda da origem bárbara. A queda do império era a restauração do mundo celtobárbaro. Eram ciclos não dialéticos, mas heterogêneos de origem, queda e restauração.

Neste momento, problematizar-se-á a relação íntima entre o político, as origens e a formação do conhecimento. O pressuposto de análise apoia-se na ideia de pertencimento, que orienta para um aspecto sociológico, que se realiza no reconhecimento de uma identidade social do habitus incorporado em um campo gestando o poder simbólico (Bourdieu, 1989) e busca pela comunidade original inocente cuja perda está envolvida na memória (Bauman, 2003). Como o conceito de pertencimento é muito abrangente, seus desdobramentos alcançam tanto a linguística como identidade epistemológica (Baronas, 2005). Uma experiência já vivida em um mesmo espaço geográfico.

Zigmunt Bauman, ao desdobrar-se sobre os aspectos mitológicos do paraíso perdido, tanto no imaginário greco-romano quanto no bíblico, aproximou-se mais das reflexões de Chantal Grell, corroborando para as leituras, análise das leituras da Antiguidade no undo moderno. De maneira especial, estes autores pensaram a memória como nostalgia do paraíso perdido e, assim, viabilizaram a formulação do conceito de 
"agenciamento das origens". Se os sujeitos procuram de forma até mesmo inconsciente um paraíso perdido, então, criar um paraíso perdido por meio de documentos viabilizaria um projeto político em meio à subjetividade dos leitores.

Em Pelloutier, o pertencimento apontava para a comunidade original. Se a comunidade original era uma aristocracia guerreira produzir-se-ia, segundo a ordem do discurso erudito, um estranhamento a uma forma política diferente. $\mathrm{O}$ estranhamento seria o duplo do pertencimento, contrário apenas nas arestas. Pertencer a um campo norteador da liberdade seria estranhar a obrigação a um culto. Pertencer à liberdade celta seria estranhar a França sob o Absolutismo.

No pensamento de Bossuet percebe-se a evocação de um pertencimento à teocracia cristã. O que faz um povo ser legítimo? O que legitima a nação? Para ele, Deus na figura de seu rei. Ao escrever a cronologia universal, a felicidade aparecia como fruto da obediência a um governante sábio e inspirado, mas também, uma obrigação do monarca. Era dever do rei a felicidade dos seus súditos. Portanto, haveria uma continuidade histórica entre Moisés (rei-profeta), as mudanças dos grandes impérios e a permanência da fé no Deus cristão.

É importante notar uma diferença epistemológica nas formas de produzir pertencimentos que seria, neste caso, a realização política do "agenciamento das origens". A diferença fundamental é a eleição do sujeito da História. O sujeito da História de Bossuet seria a religião e o político, cujo herdeiro seria o monarca. Por outro lado, o sujeito da História de Pelloutier seria o povo celta, cujos herdeiros seriam os europeus privados da liberdade pelo monarca. A eleição de um sujeito produziria não apenas uma narrativa diferente, mas a própria leitura e escolha das fontes. O espaço empírico da fonte dependeria do manuseio do seu leitor. Sujeito-leitor e fonte seriam o duplo da erudição.

O tema das origens em uma macro situação funda o "agenciamento das origens", que se dinamiza pela prática cultural da leitura cristã da origem do universo. Esta macro situação é o que se chama, nesta pesquisa, de cultura europeia. $\mathrm{O}$ símbolo das origens define, empiricamente, a territorialidade desta cultura. Na escrita da História, o tema se objetiva com o começo ideal e o fim dele derivado. Na relação com os outros povos, em especial os não cristãos e não europeus, produz-se as categorias analíticas civilizatórias, que se fundamentam no homem universal, filho de Adão. Mesmo em Lafitau, por exemplo, os americanos pertenciam ao universo cristão, pois partilhavam dos mesmos símbolos que os antigos. Eram religiosos e, por isso, tinham sentimentos 
universais. Ao reconhecer os americanos com os mesmos sentimentos universais expressos em seu próprio povo (europeu), reconhecia-se a superioridade de um sobre o outro. Se o homem era universal, o europeu era o irmão amadurecido.

Estas mudanças ganharam força e críticas na medida em que traziam discussões ao pertencimento epistemológico europeu. No entanto, a constituição antropológica da identidade do homem universal resistiu por outros estatutos, como por exemplo, aquele do regime do agenciamento das origens, que se revestia pela obrigação de se fazer a História das origens.

\section{Conclusão}

Portanto, tratou-se de uma pesquisa que procurou pela importância da Antiguidade para o estabelecimento do pensamento e das instituições modernos. Não foi apenas uma análise fenomenológica dos usos do passado, mas uma análise genealógica da inserção das condições de verdade e poder dentre de um sistema cultural $\mathrm{O}$ que faz com que estas obras sejam consideradas anti-absolutistas é o fato de pertencerem à mesma formação discursiva da propaganda historiográfica da monarquia absolutista e à inversão de seus elementos. A historiografia monárquica tentava legitimar suas pretensões absolutistas a partir de alguns fatores: da escrita da história, da origem no Império Romano, da noção de continuidade histórica e da religião católica.

Os anti-absolutistas invertem estes elementos, para eles se mantém o uso da escrita da história, da origem germânica que é contrária ao Império Romano, da noção de ruptura histórica e da crítica ao catolicismo.

Esta ordem discursiva e a inversão de elementos permitiram, a partir das fontes analisadas, a criação do conceito de agenciamento das origens. Este conceito consiste em uma ferramenta analítica para estabelecer uma compreensão da formação do conhecimento formal em meio à cultura moderna do século XVIII.

Associam-se ao agenciamento das origens os seguintes elementos: a teologia da história cristã e a taxiologia científica. Para a teologia cristã, a história começa por uma origem boa e perfeita, após vem a queda e, enfim, a restauração daquela origem. Assim, os autores compõem a história procurando sempre pela origem daquilo que pretendem analisar, podendo ser o mundo romano ou germânico, conforme o posicionamento político. Inserem uma queda, invasões bárbaras ou colonização imperial, 
por exemplo. Enfim, traçam o perfil da restauração que, efetivamente, é a ação política almejada.

Simon Pelloutier escreveu uma das fontes principais deste trabalho: Histoire des Celtes, et particulièrement des Gaulois et des Germains, depuis les temps fabuleux, jusquà la prise de Rome par les Gaulois (1740). Para este autor, a origem da França como de toda a Europa é celtogermânica, em oposição ao mundo Romano. Ao discursar isto, elabora imagem que representa no mundo celta a sua cultura protestante. Politicamente, significou uma oposição entre o mundo celta, que pare ele era aristocrático e livre, contra o mundo romano, absolutista e escravizador da população.

\section{Anexo - Fontes biográficas}

Le Moyne DES ESSARTS. Les Siècles littéraires de la France, 1800. Tomo 6.

HOEFER, JCF. Nouvelle biographie universell: depuis les temps les plus reculés jusqu'à nos jours. Paris: Firmin Didot frères, 1852-1866, tomo 46.

DEZOBRY, Charles et BACHELET, Théodore. Dictionnaire général de biographie et d'histoire, de mythologie, de géographie ancienne et moderne. Paris : Dézobry, E. Magdeleine et Cie, 1857-1861. 5a edição. Tomo 2.

DENINA, Carlo. La Prusse littéraire sous Frédéric II. Genève : Slatkine reprints, 1968.

FORMEY, Samuel. Éloge de Monsieur Pelloutier. Histoire de l'Académie Royale des Sciences et des Belles-Lettres de Berlin 1757. Berlin: Haude et Spener, 1759.

MICROFILME ABF I 818 110-122 (Bibliothèque Nationale de France).

MICROFILME DBA I 939 48-76 (Bibliothèque Nationale de France).

\section{Fontes Históricas}

BOULAINVILLIERS, H. de. Histoire De L'Ancien Gouvernement De La France: Avec XIV. Lettres Historiques sur les Parlemens ou Etats-Generaux. Haye \& a Amsthrdam (1742).

DUBOS, J. B. Histoire critique de l'établissement de la Monarchie française dans les Gaules. Paris, Chez Nyon: 1742. 3 T. 
LAFITAU, Joseph-François. Moeurs des sauvages ameriquains, comparées aux moeurs des premiers temps. Paris: Saugrain l'aíné, 1724

PELLOUTIER, Simon. Histoire des Celtes, et particulièrement des Gaulois et des Germains, depuis les tems fabuleux, jusqu'à la prise de Rome par les Gaulois. Beauregard (La Haye) 1740.

Histoire des Celtes, et particulièrement des Gaulois et des germains, depuis les tems fabuleux, jusqu'à la prise de Rome par les Gaulois. Chiniac de La Bastide: 1770-1771. 4 Tomos.

Dissertation sur l'origine des Romais. In: Histoire des Celtes, et particulièrement des Gaulois et des germains, depuis les tems fabuleux, jusqu'à la prise de Rome par les Gaulois. Chiniac de La Bastide: 1770-1771. 4 Tomos.

\section{Referências bibliográficas}

BARONAS, Roberto Leiser. Efeito de Sentido de Pertencimento à Análise de Discurso. In: II Seminário de Estudos em Análise do Discurso. Simpósio 3. Porto Alegre: UFRS, 2005. [pp. 1-14].

BAUMAN, Zygmunt. Comunidade: a busca por segurança no mundo atual. Rio de Janeiro: Jorge Zahar Editor, 2003.

BOURDIEU, Pierre. O Poder Simbólico. Tradução Fernando Tomaz. Lisboa: Difel, 1989.

DELEUZE, Gilles e GUATARI, Félix. Mil Platôs: Capitalismo e esquizofrenia. Vol. 5. Tradução: Peter Pál Pelbart e Janice Caiafa. São Paulo: Editora 34, 1997.

DUCHET, Michèle. Monde Civilisé et monde sauvage au siècle des Lumières, les fondements de l'anthopologie des Philosophes. In: $A u$ Siècles des Lumières. École Pratique des Hautes Études (SORBONNE) Institut d'Histoire Universelle de l'Academie des Sciences de l' URSS. Paris/Moscou, SEVPEN, 1970. [pp.8- 29]

ELIADE, Mircea. Myth of the Eternal Return: Cosmos and History. Translated from The French By Willard R, Trask Haener Torchrooks. Harper \& Brothers * Publishers * New York, 1958.

FORTE, Bruno. Teologia da História. Paulus: São Paulo, 2005. 
GRELL, Chantal. Histoire intellectuelle et culturelle de la France du Grand Siècle, 1654-1715. Paris, Nathan: 1997.

HAAG, Emile. La France protestante. 2e éd.Paris: Bibliothèque publique du protestantisme, 1873-1882. Tomo 3.

PÊCHEUX, Michel. Semântica e Discurso - uma crítica à afirmação do óbvio. Tradução de Eni Pulcinelli Orlandi et al. Campinas: Editora da Unicamp, 1995.

WOORTMANN, Klaas. O selvagem na "gesta Dei": história e alteridade no pensamento medieval. Revista Brasileira de História. Julio/Dezembro. 2005, vol.25, no.50, p.259-314. 